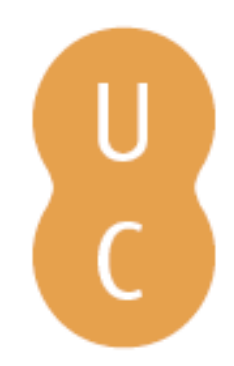

\title{
nombalina
}

\section{Criticar las religiones para bien de la "religación"}
Autor(es):
Clavel, Juan Masiá
Publicado por: Imprensa da Universidade de Coimbra
URL persistente:
URI:http://hdl.handle.net/10316.2/30088
DOI:
DOl:http://dx.doi.org/10.14195/978-989-26-0310-0_7

Accessed : $\quad$ 26-Apr-2023 10:59:09

A navegação consulta e descarregamento dos títulos inseridos nas Bibliotecas Digitais UC Digitalis, UC Pombalina e UC Impactum, pressupõem a aceitação plena e sem reservas dos Termos e Condições de Uso destas Bibliotecas Digitais, disponíveis em https://digitalis.uc.pt/pt-pt/termos.

Conforme exposto nos referidos Termos e Condições de Uso, o descarregamento de títulos de acesso restrito requer uma licença válida de autorização devendo o utilizador aceder ao(s) documento(s) a partir de um endereço de IP da instituição detentora da supramencionada licença.

Ao utilizador é apenas permitido o descarregamento para uso pessoal, pelo que o emprego do(s) título(s) descarregado(s) para outro fim, designadamente comercial, carece de autorização do respetivo autor ou editor da obra.

Na medida em que todas as obras da UC Digitalis se encontram protegidas pelo Código do Direito de Autor e Direitos Conexos e demais legislação aplicável, toda a cópia, parcial ou total, deste documento, nos casos em que é legalmente admitida, deverá conter ou fazer-se acompanhar por este aviso.

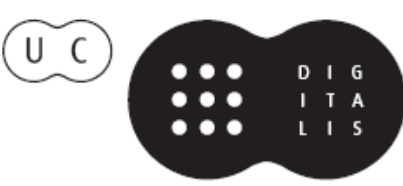




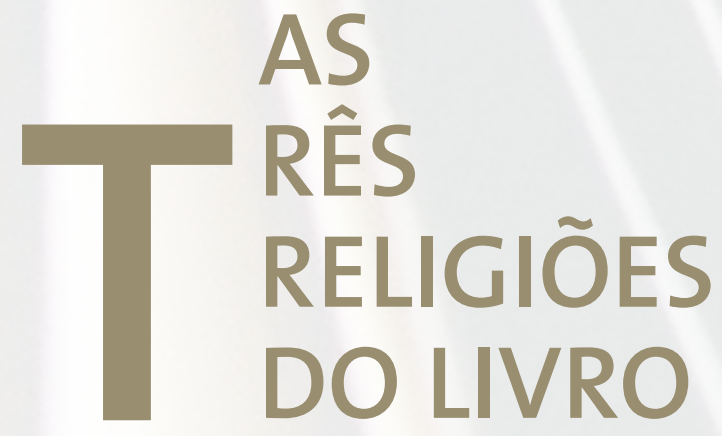

Anselmo Borges

João Gouveia Monteiro

COORDENAÇÃO 
Juan Masiá Clavel ${ }^{22}$

\section{CRITICAR LAS RELIGIONES PARA B I E N D E LA “RELIGACIÓN"}

Agradezco la oportunidad de participar en este coloquio y de compartir en esta mesa de simposio el deseo de cooperar desde la universidad a la transformación mutua de las religiones en el marco de una alianza de civilizaciones que contribuya a la paz mundial.

Dos palabras, ante todo, sobre el título de mi intervención. Las religiones, a que se refiere el título de esta breve presentación, son expresiones concretas en la historia de la relación humana con lo sagrado.

La "religación" se refiere al despertar consciente, crítico e interpretativo de la vinculación entre los interrogantes planteados por el enigma humano y el misterio de lo divino que responde a ellos con donación última de sentido.

Me pregunto: ¿Hay lugar en una mesa redonda de diálogo entre religiones para la participación de quien se dedica a la filosofía? Pienso que sí, desde una postura de mediación, con el modesto papel de facilitar críticamente el debate.

Permítanme un breve prólogo para aclarar desde qué postura pienso y hablo sobre el diálogo de religiones como persona dedicada a la filosofía, concretamente a la antropología hermenéutica.

Mi dedicación universitaria comenzó con la enseñanza de Antropología filosófica y Ética en la facultad de Filosofía. Tras una década en dicha Facultad, pasé a formar parte de la Facultad de Teología, para encargarme de cuestiones filosóficas en la Ética cristiana y en la Bioética. El tratamiento de estas cuestiones en el contexto de Japón me condujo a implicarme

22 Universidade Sophia (Tóquio). 
cada vez más en el diálogo intercultural, interreligioso, interconfesional e intercosmovisional (esta última denominación pretende incluir en el "inter" del diálogo y debate, no solamente a las religiones, sino también a todo el mundo que acostumbramos a denominar como laicidad).

Con este prólogo de propia presentación quisiera acentuar que mi perspectiva es filosófica. La filosofía es, ante todo, crítica de la vida, ya sea con la mayéutica socrática, o con la cuchilla afilada del medieval Ockham, o con la negación de negaciones del indio Nagarjuna (siglo II). La filosofía critica a la vida para bien de la misma vida. Una vida no examinada no merece la pena, diría Sócrates. La filosofía critica a las religiones, para bien de la "religación", con lo que se beneficia la religiosidad. La filosofía critica a las iglesias, con lo que se beneficia la fe. La filosofía critica las supersticiones, con lo que se depuran las creencias. La filosofía critica los excesivos entusiasmos de la mística, el peligro de fanatismo en la profecía y la bybris de autoritarismo dogmático de los sacerdocios.

Cuando el pensador Nagarjuna introduce su bisturí crítico en el cuerpo de las tradiciones budistas para operar los tumores acumulados a lo largo de su historia, había que depurar la espiritualidad budista, que tiene su fuente en la práctica y mensaje de Siddharta Gautama, el sabio de los Shaka o Shakamuni, llamado el Buda. No es un mero juego de palabras lo que hace Nagarjuna cuando repite paradójicamente: "No digo que sí, ni digo que no; no digo que sí y que no; no digo ni que sí, ni que no; tampoco digo que no ni al sí, ni al no”. Nagarjuna no está jugando con las palabras para desconcertarnos. Está practicando microcirugía sobre la tradición que hereda. Hacía falta ese examen de conciencia histórica y esa depuración de ganga y mena dentro de la tradición budista.

Tras la muerte del Buda se sucedieron corrientes de transmisión de su enseñanza. A nivel de predicación divulgadora se multiplicaron las leyendas, parábolas y florecillas pedagógicas. A nivel monástico e institucional se multiplicaron las regulaciones, preceptos y ritos. A nivel de religiosidad popular, se produjeron sincretismos prodigiosos con tradiciones politeístas. A nivel especulativo se desarrolló toda una escolástica tan complicada como la del Abhidharma, que deja pequeñas a las teorizaciones del cristianismo medieval. A nivel místico, surgió una inmensa literatura sapiencial, los sutras de la sabiduría. 
Frente a todos esos desarrollos en diversos los niveles, tenía que levantarse la voz y el pensamiento crítico de Nagarjuna para criticarlos a todos, porque en todos hay un exceso, una exageración y una bybris. Diversas expresiones de la religión, populares o intelectuales, interiorizaciones místico-sapienciales o proyecciones sociales compasivas y liberadoras, moldes institucionalizados o libertades carismáticas, etc... ninguna está libre de exageraciones y, por eso, a todas apunta el disparo de la crítica de Nagarjuna. Ya sean monjes y monjas o laicos y laicas, ya sean reyes, sacerdotes o profetas, tanto de Oriente como de Occidente, no tienen derecho a patente de corso para navegar por los mares de la espiritualidad sin pasar por el control aduanero de la filosofía. Esta es la tesis aprendida de las negaciones de Nagarjuna y las preguntas de Sócrates, de los silencios del Buda y las parábolas de Jesús.

\section{Matizaciones sobre lo místico y lo profético}

Se nos ha dado como frase emblemática para el presente simposio el contraste entre religiones místicas y religiones proféticas. Tengo reservas acerca de esta distinción cuando se aplica como clasificación rígida. Cuestionar esta tipología nos llevaría muy lejos. Me limito a dejar constancia de las precisiones siguientes.

Ante todo, en vez de clasificar las religiones en místicas y proféticas, sería preferible hablar de aspectos místicos y proféticos de la religiosidad y espiritualidad en diversas manifestaciones sociales e históricas de diversas religiones.

También habría que evitar la identificación reduccionista de lo místico-sapiencial solamente con algunas manifestaciones religiosas, ya sean de la India o del Extremo Oriente o del Medio Oriente. (En realidad, más que el contraste entre religiones místicas y proféticas, el desafío fuerte para las tradiciones judeo-cristiana e islámica sería el encuentro a fondo con formas de religiosidad "no-teísticas", por así decirlo).

Además, dentro de una misma religión, hay que reconocer que los aspectos místicos y proféticos pueden manifestarse de diversas maneras según la variedad de épocas, lugares o relaciones interpersonales y sociales.

Dicho esto, se puede admitir el predominio, en tradiciones como las del Yoga, Taoismo o Budismo Zen, de los rasgos englobables con el denominador 
común de lo místico-sapiencial en un sentido muy amplio. Pero sin olvidar que los dos pilares de la lucidez y la compasión, el desengaño y la misericordia, el despertar de la ilusión y la liberación del sufrimiento, repercuten socialmente en la liberación humana integral, aunque lo hagan en una clave y a un nivel diferente del de los profetas israelitas. (Es el caso del llamado "budismo comprometido socialmente", engaged buddhism).

Hechas estas matizaciones, sería importante reconocer explícitamente que tanto las religiones etiquetadas convencionalmente como místicas, así como las clasificadas con el letrero de proféticas, u otras que no encajen en dichas tipologías, todas sin excepción necesitan hoy día redescubrir la autenticidad mística (interioridad) y la genuina praxis profética (socialidad) como tarea urgente del presente siglo, más allá del mero diálogo interreligioso. Todas las religiones heredan tradiciones de paz, pero todas ellas a lo largo de la historia se han desviado de sus raíces y han caído en la violencia: violencia en el interior de la propia religión, violencia entre las religiones y violencia entre las religiones y la sociedad. Está por resolver el problema de si las causas de estas violencias son meramente coyunturales o se insertan estructuralmente en la religión misma. Habrá que continuar la tarea de dilucidar esta cuestión en el lugar privilegiado del encuentro intercultural e intercosmovisional de las religiones, oportunidad para su transformación mutua en beneficio del redescubrimiento de la "religación".

Pero retomando el hilo de este prólogo, diré que, desde la postura filosófica, he reflexionado sobre el tema de hoy: lo místico y lo profético. Para poder compartir con quienes participan en este coloquio esa reflexión en solo unos minutos, la resumo en las proposiciones siguientes.

\section{Tres propuestas desde la filosofía sobre el diálogo interreligioso}

Mi reflexión se puede resumir en tres puntos:

1. El encuentro interreligioso no es suficiente.

2. Hace falta reflexión autocrítica en el seno de cada religión.

3. La filosofía ayudaría a discernir las ideologías dentro de las religiones. 
En primer lugar, el encuentro interreligioso entre religiones con predominio del aspecto místico y de religiones que acentúan los rasgos proféticos no parece suficiente para superar las desviaciones fanáticas, exclusivistas o intolerantes que se han dado en la historia de casi todas ellas.

En segundo lugar, hay que decir que es necesario un pensamiento autocrítico y hermenéutico para discernir en el interior de cada religión sus desviaciones y autoengaños. No propongo que absoluticemos la crítica de la modernidad, ni tampoco que nos quedemos en ella; solamente pretendo constatar que las religiones que no pasen por esa etapa crítica, seguirán sin aprobar la asignatura pendiente: la tolerancia, la apertura al pluralismo y a dejarse transformar por lo diferente, atreviéndose a "renegociar" psicológica y sociológicamente su identidad.

Finalmente, ayudará para esta tarea que la filosofía discierna a las llamadas "religiones monoteístas del libro" y a las religiones incluidas bajo el común denominador de "espiritualidades no-teistas". Ambas se pueden influir y fecundar mutuamente. La reflexión crítica de la filosofía será un reto para ambas y, a la vez, una ayuda para explorar el futuro de las religiones o, en su caso, el futuro de nuevas formas de espiritualidad, religiosidad o "religación" más allá de las religiones.

\section{Un ejemplo: también hay violencia en tradiciones "místico-sapienciales"}

Da mucho qué pensar el libro de Brian Daizen Victoria23 sobre el uso y manipulación violenta y militarista del Zen. Esta obra nos hace pensar sobre la doble posibilidad pacificadora y violenta de la mística Zen y, por consiguiente, de la necesidad de discernir la autenticidad de esa espiritualidad para depurarla de deformaciones contradictorias con su espíritu. Fue muy controvertida cuando se publicó en 1997 y todavía se ha puesto de mayor actualidad su segunda edición en el 2006, en el contexto de los intentos actuales de justificación religiosa de violencias, terrorismos y guerras. El autor habla desde su propia postura como monje del Zen, de la secta

\footnotetext{
23 Brian Daizen Victoria, Zen at War, Rowman and Littlefield Publishers, Oxford, 2006.
} 
Soto; ve como incompatible con su religiosidad el apoyo de su propia secta al nacionalismo militarista japonés. Tras más de un cuarto de siglo de investigación, pone de manifiesto las raíces de esta desviación en el seno de la religión, a la vez que expone las dificultades que encontraron quienes desde dentro de la misma religión alzaron sus voces proféticas en sentido contrario.

La obra de B. D. Victoria se ocupa de la época conocida en la historia de Japón como la era de Meiji (1868-1945), durante la cuál el budismo pagó el precio por su supervivencia a costa de ceder demasiado ante la ideología política gobernante. El autor hace ver que estos compromisos dañaron al propio budismo aún más que las mismas amenazas o persecuciones.

Si el exceso de lógica racionalizadora ha llevado en el cristianismo a justificaciones de violencia, en el budismo se ha llegado a algo semejante por el extremo contrario: el descuido del pensamiento crítico. Si la doctrina de la vía media puede ser muy sana y equilibrada, un mal uso de ella conduce a no comprometerse con ninguna postura definida para evitar cualquier confrontación. Eso cierra el camino a cualquier oposición, a la denuncia profética o a las reivindicaciones y deja la puerta abierta a la sumisión ante gobiernos dictatoriales.

Pacificarse y pacificar son grandes valores budistas, pero un nirvana mal entendido puede conducir a una paz de muerte o de sueño, a no fomentar la promoción de la justicia ni la reivindicación de los derechos, ni a construir una paz sin discriminaciones.

En la conclusión, el autor reconoce que, como monje budista que es, ha sido duro para él escribir esta obra, porque le obligaba a revelar el lado oscuro de su propia religión. Le gustaría poder decir que las declaraciones de arrepentimiento recientes han dejado cerrado el caso; pero cree que el problema tiene raíces más hondas.

\section{Otro ejemplo: religiones monoteístas y no-teistas en debate interactivo}

A continuación, otro ejemplo. Reproduzco brevemente, aunque sea de forma algo simplificada y estereotipada, una experiencia que he tenido en más de un simposio interreligioso en Japón con participación de representantes 
de "Oriente" y "Occidente" (Entre comillas, para no olvidar que estas nociones no son geográficas, ya que Oriente tiene mucho de Occidente y viceversa). Lo diré esquemáticamente a grandes rasgos:

Estábamos reunidos representantes de teología y filosofía de diversas religiones en una mesa redonda, en Kyoto, hace tres años. Tras la intervención de un budista, pide la palabra un teólogo cristiano para decir que le ha producido la impresión de panteísmo. Un filósofo occidental levanta la mano para preguntar al mismo ponente si su noción de la Nada y el Vacío es una forma de nihilismo. El budista responde clara y sinceramente que no le han entendido. A continuación, hablan representantes del judaismo, cristianismo e islam. A la hora de las preguntas, voces budistas dicen que "las tres religiones del libro" les parecen dualistas, muy personalistas y proclives al exclusivismo y la intolerancia. Ahora son estas últimas quienes dicen "no nos han entendido".

Esta escena, que acabo de estereotipar exageradamente, no hace más que acentuar, como todas las caricaturas, unos rasgos muy típicos de la impresión que produce el rostro diferente. Por eso lo reconocemos en la caricatura, aunque admitamos que ésta no es una fotografía, ni equivale a la realidad.

La repetición en varias ocasiones de escenas de debate interreligioso como la que acabo de caricaturizar me ha llevado a las reflexiones siguientes:

A) Ante el reto del encuentro con religiosidades orientales, a las tres religiones monoteistas abrahámicas se les plantea la revision de lo que, visto desde fuera, produce la impresión (desmentida por sus apologetas) de ser un personalismo demasiado antropomórfico y un moralismo demasiado preceptista en las formas de vivir y expresar su fe.

B) Ante el reto del encuentro con las tres religiones monoteistas abrahámicas, a las llamadas religiones orientales se les plantea la revision de lo que, visto desde fuera, produce la impresión (desmentida por sus apologetas) de nihilismo metafísico y relativismo moral.

C) Al compartir y reflexionar en común sobre la historia de unas y otras religiones, tanto las de tradición abrahámica monoteista como las de tradición budista, se ven obligadas a reconocer la traición histórica de las religiones a la religiosidad, sobre todo por lo que se refiere a los 
problemas de la manipulación política de la religión o la manipulación religiosa de la política, con la consiguiente repercusión en la práctica de la violencia. Sería demasiado simplista vincular la violencia con la esencia de los monoteismos y seria ingenuo idealizar las tradiciones orientales como prototipos de no violencia. Desde una ética laica acompañada de crítica histórica habría que criticar las desviaciones violentas de unas y otras religiones cada vez que han traicionado el llamado religioso a la paz interior y a la pacificación social.

Volviendo al ejemplo del simposio de la caricatura anterior, decía un interlocutor budista que los cristianos parecemos demasiado tajantes en dogma y moral y demasiado antropomórficos al hablar de la divinidad y sus relaciones con el mundo y la sociedad. Pero, por otra parte, en conferencias de divulgación sobre budismo en paises occidentales, nos preguntan a menudo si el budismo es panteista o nihilista, y también nos preguntan sobre la impresión de relativismo y sincretismo. Reconozco que, en el primer caso, brota una reacción espontánea de hacer apologética, tratando de corregir la impresión producida por el monoteismo entre los orientales. También hay que admitir que, en el segundo caso, en cambio, surge una reacción espontánea de simpatizar con lo oriental y hacer igualmente apologética en su favor.

Sin embargo, en un segundo momento, tratando de superar o al menos frenar estas tentaciones apologéticas de uno y otro lado, uno reconoce que ambos cuestionamientos obligan a la autocrítica y la revisión a ambas partes. Y de ahí han surgido algunas de las reflexiones hechas más arriba.

Pienso que en estos debates interculturales e interreligiosos tenemos todos que renunciar a decir la ultima palabra y dejarnos mas bien influenciar y transformar mutuamente para seguir creciendo humana y religiosamente.

\section{Mística y crítica}

Diré como conclusión que, para evitar la tergiversación violenta de las tradiciones de paz, las religiones necesitan redescubrir el presupuesto 
místico y el acompañamiento crítico: en el budismo, iluminación y compasión conjugadas; en el cristianismo, conversión y discernimiento hermanados. Lo resumiría con dos pares de nociones claves en dos obras clásicas de espiritualidad: "conversión y discernimiento", en los Ejercicios espirituales de Ignacio de Loyola; y "samadhi y vispasyana", en Pararse a contemplar, del monje chino Chih-I. En Ignacio, había dos vivencias fundamentales: la de un encuentro que cambia la vida y lleva a una conversión, y la de percatarse de los autoengaños en el momento siguiente, por lo que se hace necesaria la crítica que discierne. Para Chi-I (538-597), la receptividad de la iluminación y la crítica que descubre un nuevo modo de mirar son complementarias (en japonés, shi-kan, shi: pararse; y kan: mirar; es decir, detenerse a respirar y a contemplar o mirar de otro modo, el momento contemplativo y crítico, respectivamente).

Esta conjugación de mística y crítica evitaría que las religiones se conviertan en ideologías y, por consiguiente, justifiquen las violencias.

El peligro de desvirtuarse la religiosidad y convertirse en violencia acecha cuando se olvida el presupuesto místico y cuando falta el acompañamiento crítico. En el caso de la fe cristiana a lo largo de la historia occidental, cuando se ha convertido en ideología ha dado lugar a justificaciones de la violencia. También en Oriente, la religiosidad budista ha caído en semejante trampa cuando se ha convertido en ideología. Ambas tradiciones religiosas han sido manipuladas en esos casos por las instancias del poder fáctico y han acabado por ceder a compromisos que entraban en contradicción con su propia espiritualidad. Sin renunciar a la propia tradición espiritual, pero dejándose transformar mutuamente en contacto con otras espiritualidades, unas y otras tendrán que evitar convertirse en ideologías. Para ello quisiera contribuir la aportación de la filosofía como crítica de las ideologías.

No puedo alargarme más. Solamente he sugerido una perspectiva y aducido un par de ejemplos. No es posible desarrollar esta temática en el breve tiempo disponible. Me daría por satisfecho si esta sencilla aportación sirviera para fomentar la participación crítica y creativa, mediadora e interpretativa, de la filosofía en los diálogos y debates interreligiosos, con 
el fin de ayudar al discernimiento de las ideologías y a la transformación mutua de las religiones, para bien de la "religación" del enigma humano con el misterio de lo sagrado que repercuta en una praxis de pacificarse y pacificar mundialmente. 